\title{
CLINICAL AND MICROBIOLOGICAL EFFECTIVENESS OF CHLORHEXIDINE AND SODIUM HEXAMETAPHOSPHATE MOUTH RINSES ON DENTAL PLAQUE IN CHILDREN
}

\author{
Diana Sabri Hedihed*, Mohamed Sherif Farag**, Shadeed Gad Abdelrahman**** \\ and Shaimaa Mohamed Mahfouz Omer****
}

\begin{abstract}
Introduction: The use of a mouthwash augments mechanical removal of plaque by brushing and flossing and helps maintain oral health through its antiplaque and antibacterial chemical properties.
\end{abstract}

Aim: to evaluate and compare clinically and microbiologically the effectiveness of chlorhexidine and sodium hexametaphosphate mouth rinses on dental plaque in children.

Materials and methods: This randomized clinical trial involved 40 normal apparently healthy and cooperative children aged 8 to 10 years and chosen from the Outpatient Dental Clinic of Pediatric dentistry Department, Faculty of Dentistry, Suez Canal University. Children were randomly divided into 2 groups as follows: Group I: included (20) children who rinsed with Chlorhexidine $(0.2 \%)$ and Group II: included (20) children who rinsed with Sodium Hexametaphosphate (7\% ). Clinical evaluation was performed by measuring gingival and plaque indices scores at all evaluation periods. Microbiological evaluation was performed by direct examination of bacterial cultures.

Results: Sodium hexametaphosphate $7 \%$ mouth rinse showed a superior effect compared to chlorhexidine $0.2 \%$ mouth rinse in terms of improvement in the clinical scores and decreasing the microbial counting.

Conclusion: Sodium hexametaphosphate $7 \%$ mouth rinse is a promising candidate of mouthwashes.

KEYWORDS: Chlorhexidine; Dental plaque; Lactobacillus; Sodium Hexametaphosphate; Streptococcus mutans.

\footnotetext{
* B.D.S. Suez Canal University 2009, General Dental Practitioner in the Ministry of Health.

** Professor of Pediatric and Preventive Dentistry and Dental Public Health, Faculty of Dentistry, Suez Canal University.

*** Associate Professor of Pharmaceutics and Industrial Pharmacy, Faculty of Pharmacy, Suez Canal University. **** Lecturer of Pediatric and Preventive Dentistry and Dental Public Health, Faculty of Dentistry, Suez Canal University.
} 


\section{INTRODUCTION}

Dental plaque is a biofilm that is naturally formed on surfaces of teeth and other parts of the oral cavity. It is considered as the main etiological factor for oral diseases; specially dental caries and periodontal diseases ${ }^{(1)}$.

Mechanical plaque control is the mainstay for prevention of oral diseases, but it requires patient cooperation and motivation; therefore, chemical plaque control is used for achieving the desired results. ${ }^{(2)}$ Chemotherapeutic agents may be used to reduce, eliminate or change the quality of microbial pathogens. In addition, they alter the host response through local or systemic delivery of appropriate agents. ${ }^{(3)}$ Chlorhexidine is one of the most frequently used compounds. It is a broad spectrum antiseptic with strong antimicrobial effects on both Grampositive as well as Gram-negative bacteria and some viruses. ${ }^{(4)}$

Chlorhexidine remains in the oral cavity several hours after application that makes it a useful agent for prevention of plaque regrowth and bacterial colonization. ${ }^{(5)}$

On the other hand, chlorhexidine has some disadvantages; it irritates the oral mucosa and this is not dosage dependent. Tooth discoloration, sensitivity changes, taste perturbation, unilateral, or bilateral parotid swelling and tongue pain may occur as side effects leading to search for new formulations. ${ }^{(6)}$

The addition of inorganic polyphosphate salts (including sodium hexametaphosphate) to fluoridated products has been shown to be effective in increasing their effectiveness against caries. ${ }^{(7)}$ Sodium hexametaphosphate (SHMP) is able to inhibit the formation of dental calculus, ${ }^{\left({ }^{8}\right)}$ has antimicrobial action ${ }^{(9)}$ and also prevents the formation of extrinsic stains. SHMP has greater possibility of binding to the enamel surface and protecting it from acid dissolution. ${ }^{(10)}$
The aim of this study was to compare and evaluate the effect of chlorhexidine and sodium hexametaphosphate mouth rinses on dental plaque in children.

\section{MATERIALS AND METHODS}

This study was a randomized clinical trial involving 40 normal apparently healthy and cooperative children aged from 8-10 years from both sexes from those attending Outpatient Clinic of Pediatric and Preventive Dentistry and Dental Public Health Department, Faculty of Dentistry, Suez Canal University. Adequate diagnosis and treatments planning were performed. Each selected child was subjected to full mouth treatments if needed until we had all the selected patients with no caries.

\section{Inclusion criteria:}

- Either caries free children or previously treated children.

- $\quad$ Age from 8-10 of both sexes.

- Apparently healthy children.

- No systemic diseases, children took antibiotic, steroid therapy or any anti-inflammatory drugs for the last 3 weeks.

- Child with full eruption of upper left permanent first molar, upper left permanent lateral incisor, upper right primary first molar, lower right permanent first molar, lower right permanent lateral incisor and lower left primary first molar.

\section{Exclusion criteria:}

- Children with orthodontic appliances or with intra oral prosthesis.

- Un cooperative children or children who cannot attend the follow up visits.

- Children had a history of fluoride treatment in the past 2 weeks.

- Allergy to any dental products or their ingredients. 
- Patients with missing upper left permanent first molar or upper left permanent lateral incisor or upper right primary first molar or lower right permanent first molar or lower right permanent lateral incisor or lower left primary first molar.

Informed consent, both written and verbal, was obtained from both the parent and the children before enrolling in the study. Each child was instructed to brush his or her teeth with a toothbrush wetted with water using Stillman's brushing technique. Tooth brushing technique and mouth rinsing method were demonstrated for every child. Children were instructed to brush and rinse twice daily in the morning and evening for two weeks. They were instructed to rinse with $15 \mathrm{ml}$ of the solution for $1 \mathrm{~min}$ followed by expectoration of the residual mouth rinse and they were asked not to eat or drink anything for $30 \mathrm{~min}$ after using the mouthwash for collection of plaque samples. During the treatment period there was not any other oral hygiene measure. ${ }^{(11,12)}$

Children were randomly divided into 2 groups as follows:

- Group I: included (20) children who rinsed with Chlorhexidine $(0.2 \%)$.

- Group II: included (20) children who rinsed with Sodium Hexametaphosphate (7\%).

\section{Preparation of chlorhexidine $(0.2 \%)$ mouth wash}

Mouth wash containing chlorhexidine was formulated by the following formula. ${ }^{(13)}$ A calculated amount of surfactant was heated and transferred to the main container. Sorbitol was diluted with distilled water and added to the main container. In other containers, Sodium benzoate and Sodium saccharine were dissolved, filtered and added to the main container. Chlorhexidine was diluted with water, filtered and added to the main container. Finally flavouring agent and colour were dissolved separately, filtered and added to the main container.
The total volume was adjusted using distilled water. The final product was analyzed and filled in suitable bottles.

\section{Preparation of Sodium Hexametaphosphate (7\%) mouth wash:}

Mouth wash containing Sodium hexametaphosphate was formulated by the following formula ${ }^{(13)}$ A calculated amount of surfactant was heated and transferred to the main container. Sorbitol was diluted with distilled water and added to the main container. In other containers, Sodium benzoate and Sodium saccharine were dissolved, filtered and added to the main container. Sodium hexametaphosphate was diluted with water, filtered and added to the main container. Finally, flavouring agent and colour were dissolved separately, filtered and added to the main container. The total volume was adjusted using distilled water. The final product was analyzed and filled in suitable bottles.

\section{Methods of evaluation:}

All children were evaluated clinically and microbiologically at (the base line) a day before using mouth washes, then at 7 th and 15 th day after mouth rinsing..

\section{A- Clinical evaluation:}

Clinical evaluation by measuring gingival and plaque indices scores was done as follows:

\section{Gingival index: ${ }^{14}$}

Gingival index (Loe H. and Silness J.1963) was used to evaluate the gingival condition and record qualitalization changes in the gingiva. The examination was done by blunt probe and partially erupted teeth was excluded. The selected teeth were upper left permanent first molar, upper left permanent lateral incisor, upper right primary first molar, lower right primary first molar. The selected surfaces were buccal, lingual, mesial and distal. 
Turesky, Gilmore, Glickman modification of the Quigley Hein Plaque Index (Turesky et al. Modified Quigley Hein Plaque Index): ${ }^{(15)}$

A disclosing agent was used for plaque detection. Children were instructed to rinse with the disclosing agent. The selected teeth were the same used above in the gingival index. Plaque was assessed on the labial, mesial, distal and lingual surfaces of the teeth after using a disclosing agent.

\section{B- Microbiological analysis}

\section{I- Collection of specimens:}

Sterile cotton swab fixed on a wooden stick was streaked across the entire labial tooth surface of the lower anteriors (incisors) from distal to mesial in a horizontal direction while exerting pressure on the swab getting as close as possible to the gingival margin without touching it (supragingival plaque). All the samples were aseptically processed and tested for the isolation, identification and colony counts of Streptococcus mutans and Lactobacillus species.

\section{II-Streptococcus mutans isolation and identification:}

Streptococcus mutans are facultative anaerobic Gram-positive coccus-shaped bacteria and their optimal growth is at $37^{\circ} \mathrm{C}$. On mitis salivarius agar, the colonies of Streptococcus mutans are small, raised, irregularly margined and adherent. ${ }^{(16,17)}$

\section{Preparation of mitis salivarius bacitracin (MSB) agar:}

Mitis salivarius agar was used to selectively enumerate Streptococcus mutans in swaps from dental plaque. ${ }^{(18)}$ The MSB medium was prepared according to the instructions of the manufacturer.

\section{III-Lactobacilli isolation and identification:}

Lactobacilli are long, slender, non-spore forming, Gram-positive rods that are generally facultative anaerobic, most of which grow well with reduced oxygen tension and increased $\mathrm{CO} 2$. Lactobacilli grow on a variety of media including Rogosa agar where they appear as white, usually mucoid colonies. ${ }^{(19)}$

\section{Preparation of Rogosa agar:}

Rogosa agar was used to selectively enumerate lactobacilli in the swaps from dental plaque. ${ }^{(20)}$ The medium was prepared according to the instructions of the manufacturer.

\section{IV-Processing of the Specimens:}

1. Swabs were placed into tubes containing $5 \mathrm{ml}$ tryptone soya broth. Samples were vortexed for 30 seconds to mix them thoroughly.

2. For quantitative bacterial assessment, sterile disposable calibrated loops $1 / 100$ and $1 / 1000 \mathrm{ml}$ were used to transfer and streak swab specimens into freshly prepared MSB and Rogosa agar plates.

3. (MSB) agar plates were incubated anaerobically at $37^{\circ} \mathrm{C}$ for $48-72$ hours.

4. Rogosa agar plates were incubated anaerobically in anaerobic jar using anaerobic gas pack and plates were incubated at $37^{\circ} \mathrm{C}$ for $48-72$ hours.

5. After incubation, a colony counter with magnifying glass was used to count the number of colonies and they were expressed as the number of colony forming units per $\mathrm{ml}$ (CFU/ $\mathrm{ml}$ ) of sample. By multiplying the actual colony count by $10^{2}$ or $10^{3}$ (according to the used calibrated loop) quantification of the number of colonies was done. ${ }^{(21)}$

\section{Statistics:}

Statistical presentation and analysis of the present study was conducted, using the mean, standard deviation, student t- test, Paired t-test by SPSS V20. $\quad \sum x$

1. $\underline{\text { Mean }}=\mathrm{n}$ 
Where $\Sigma=$ sum $\& \mathrm{n}=$ number of observations.

1. $\underline{S D=} \sqrt{\frac{\sum|\mathrm{x}-\mathrm{x}|^{2}}{n-1}}$ ion [SD] :

Student t-test [Unpaired]:

$t=\frac{\overline{\mathrm{X}}_{1}-\overline{\mathrm{X}}_{2}}{\sqrt{\mathrm{SE}_{1} 2+\mathrm{SE}_{2} 2}}$

Where:

$\bar{X}_{1}=$ Mean of the first group .

$\bar{X}_{2}=$ Mean of the second group .

$\mathrm{SE}_{1}=$ Standard error of the first group.

$\mathrm{SE}_{2}=$ Standard error of the second group.

Unpaired Student T-test was used to compare between two groups in quantitative data.

\section{Paired t-test}

$t=\frac{\overline{\mathrm{X}} \mathrm{d}}{\sqrt{\mathrm{SE}_{\mathrm{d}}}}$

Where:

$\bar{X}_{d}=$ Mean's difference between pre and post .

$\mathrm{SE}_{\mathrm{d}}=$ Standard error of the difference between pre and post.

Unpaired Student T-test was used to compare between related sample

$$
\begin{aligned}
& \mathrm{P} \text {-value }>0.05 \text { Non significant } \\
& \text { P-value } \leq 0.05 \text { Significant } \\
& \text { P-value }<0.01 \text { Highly Significant }
\end{aligned}
$$

\section{RESULTS}

\section{Clinical results}

Evaluation of clinical parameters (gingival and plaque indices scores) was done for all the treated groups at baseline, 7 day and 15 day according to the gingival index system and Turesky et al Modified Quigley Hein Plaque Index system respectively.

\section{Gingival index results:}

Group I and group II showed a decrease in the mean value of gingival index form baseline to 7 days, from 7 days to 15 days and from baseline to 15 days. This decrease was highly statistically significant difference*** as shown in table (1).

In between groups, there was a highly statistical significant decrease ${ }^{* *}$ in the mean of gingival index when comparing between group II and group I at all evaluation periods (after 7 days and 15 days) as shown in table (1).

\subsection{Turesky et al. Modified Quigley Hein Plaque Index results:}

Group I and Group II showed a decrease in the mean value of plaque index form baseline to 7 days, from 7 days to 15 days and from baseline to 15 days. This decrease was highly statistically significant difference** $^{* *}$ as shown in table $(2)$ and figures $(1,2)$.

In between groups, at the 7th day there was a statistical significant decrease* in the mean value of plaque index in group II when compared with its corresponding value in group I.

At the 15th day there was highly statistically significant decrease ${ }^{* *}$ in the mean value of plaque index in group II when compared with its corresponding value in group I as shown in table (2).

\section{2- Microbiological results}

\subsection{Streptococcus mutans count:}

The mean value of $S$. mutans count in both group I and group II showed a highly statistically significant decrease** from 7 days to 15 days and from baseline to 15 days as shown in table (3) and figures $(3,4)$.

In between groups, there was a highly statistical significant decrease** in the mean of $S$. mutans count when comparing between group II and group I at all evaluation periods (after 7 days and 15 days) as shown in table (3). 
TABLE (1): Comparison between mean values of gingival index in group I and group II measured at different times of evaluation.

\begin{tabular}{|c|c|c|c|c|c|c|}
\hline & \multirow{2}{*}{\multicolumn{2}{|c|}{ Gingival index }} & \multicolumn{2}{|c|}{ Groups } & \multicolumn{2}{|c|}{ T-Test } \\
\hline & & & group I & group II & $\mathrm{T}$ & P-value \\
\hline \multirow{2}{*}{\multicolumn{2}{|c|}{ Baseline }} & Range & $0.41-0.81$ & $0.04-0.79$ & \multirow{2}{*}{-1.572} & \multirow{2}{*}{0.124} \\
\hline & & Mean \pm SD & $0.09 \pm 0.57$ & $0.17 \pm 0.50$ & & \\
\hline \multirow{2}{*}{\multicolumn{2}{|c|}{ After 7 Days }} & Range & $0.17-0.71$ & $0.13-0.54$ & \multirow{2}{*}{-4.145} & \multirow{2}{*}{$0.001 * *$} \\
\hline & & Mean \pm SD & $0.12 \pm 0.47$ & $0.12 \pm 0.31$ & & \\
\hline \multirow{2}{*}{\multicolumn{2}{|c|}{ After 15 Days }} & Range & $0.13-0.58$ & $0.04-0.38$ & \multirow{2}{*}{-4.435} & \multirow{2}{*}{$0.001 * *$} \\
\hline & & Mean \pm SD & $0.11 \pm 0.31$ & $0.11 \pm 0.15$ & & \\
\hline \multirow{2}{*}{ B-7D } & Differences & Mean \pm SD & $0.10 \pm 0.05$ & $0.19 \pm 0.11$ & & \\
\hline & Paired Test & P-value & $0.001 * *$ & $0.001 * *$ & & \\
\hline \multirow{2}{*}{ B-15D } & Differences & Mean \pm SD & $0.26 \pm 0.06$ & $0.34 \pm 0.13$ & & \\
\hline & Paired Test & P-value & $0.001 * *$ & $0.001 * *$ & & \\
\hline \multirow{2}{*}{$7-15 \mathrm{D}$} & Differences & Mean \pm SD & $0.16 \pm 0.06$ & $0.15 \pm 0.05$ & & \\
\hline & Paired Test & P-value & $0.001 * *$ & $0.001 * *$ & & \\
\hline
\end{tabular}

The group I = Chlorhexidine group - The group II = Sodium Hexametaphosphate group

$P$-value $>0.05$ Non significant

TABLE (2): Comparison between mean values of Turesky et al Modified Quigley Hein Plaque Index in the group I and group II measured at different times of evaluation.

\begin{tabular}{|c|c|c|c|c|c|c|}
\hline \multirow{2}{*}{\multicolumn{2}{|c|}{ Plaque index }} & & \multicolumn{2}{|c|}{ Groups } & \multicolumn{2}{|c|}{ T-Test } \\
\hline & & & \multirow{2}{*}{$\begin{array}{c}\text { Group I } \\
0.63-1.5\end{array}$} & \multirow{2}{*}{$\begin{array}{c}\text { Group II } \\
0.5-1.54\end{array}$} & \multirow{2}{*}{$\begin{array}{c}\mathrm{T} \\
-0.671\end{array}$} & \multirow{2}{*}{$\begin{array}{c}\text { P-value } \\
0.506\end{array}$} \\
\hline Baseline & & Range & & & & \\
\hline & & Mean \pm SD & $0.22 \pm 0.96$ & $0.29 \pm 0.91$ & & \\
\hline \multirow[t]{2}{*}{ After 7 Days } & & Range & $0.42-1.17$ & $0.25-1.13$ & -2.307 & $0.027 *$ \\
\hline & & Mean \pm SD & $0.18 \pm 0.73$ & $0.22 \pm 0.58$ & & \\
\hline \multirow[t]{2}{*}{ After 15 Days } & & Range & $0.13-0.96$ & $0.04-0.79$ & -2.709 & $0.010 * *$ \\
\hline & & Mean \pm SD & $0.19 \pm 0.52$ & $0.18 \pm 0.35$ & & \\
\hline \multirow[t]{2}{*}{ B-7D } & Differences & Mean \pm SD & $0.23 \pm 0.12$ & $0.32 \pm 0.13$ & & \\
\hline & Paired Test & P-value & $0.001 * *$ & $0.001 * *$ & & \\
\hline \multirow[t]{2}{*}{ B-15D } & Differences & Mean \pm SD & $0.44 \pm 0.16$ & $0.55 \pm 0.20$ & & \\
\hline & Paired Test & P-value & $0.001 * *$ & $0.001 * *$ & & \\
\hline \multirow[t]{2}{*}{$7-15 \mathrm{D}$} & Differences & Mean \pm SD & $0.21 \pm 0.06$ & $0.23 \pm 0.10$ & & \\
\hline & Paired Test & P-value & $0.001 * *$ & $0.001 * *$ & & \\
\hline
\end{tabular}

The group I = Chlorhexidine group, group I = Sodium Hexametaphosphate group

P-value $>0.05$ Non significant $* P$-value $\leq 0.05$ Significant $*$ * P-value $<0.01$ Highly Significant 


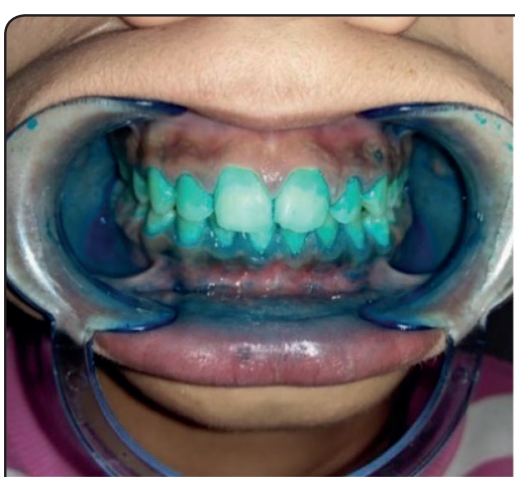

Base line

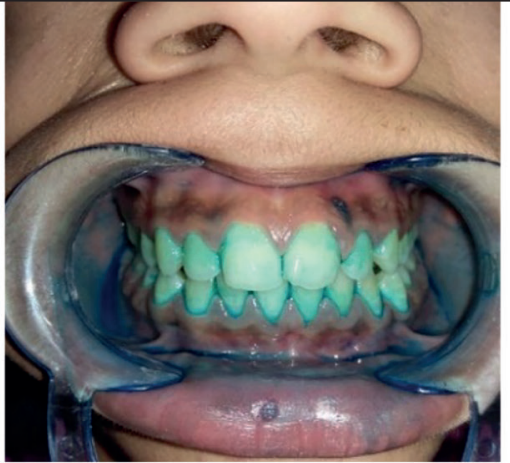

Day 7

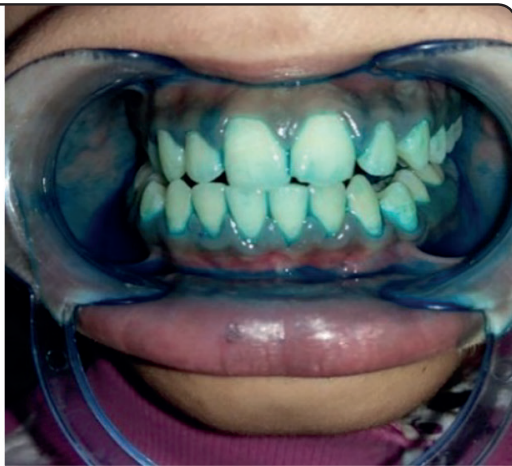

Day 15

Fig. (1) Showing patient 10 years old showing staining of microbial biofilm in dental plaque with disclosing agent at base line, day 7 and day 15 (group I).

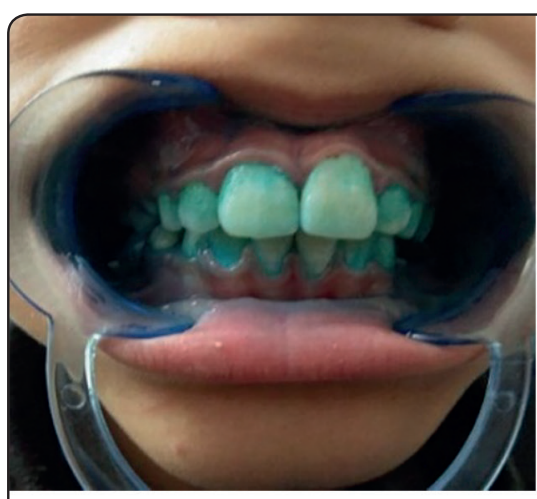

Base line

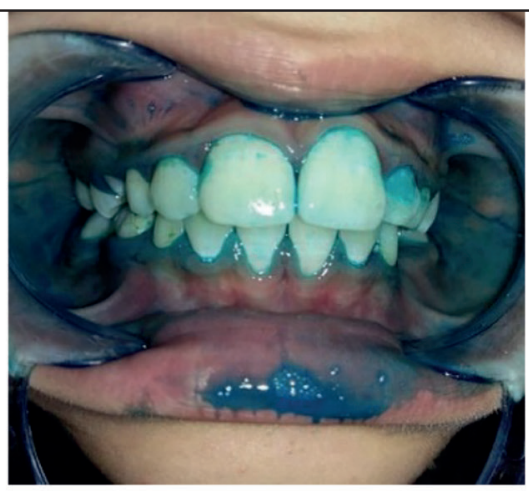

Dav 7

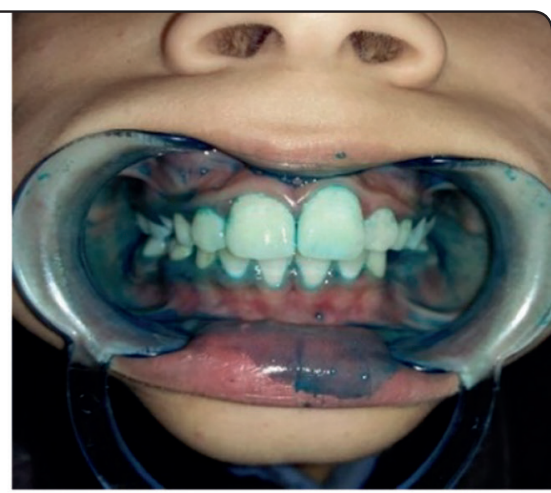

Dav 15

Fig. (2) Showing patient 10 years old showing staining of microbial biofilm in dental plaque with disclosing agent at base line, day 7 and day 15 (groupII).

TABLE (3): Comparison between S. mutans count in group I and group II measured at different times of evaluation.

\begin{tabular}{|c|c|c|c|c|c|c|c|c|c|c|}
\hline \multirow{2}{*}{\multicolumn{2}{|c|}{ S. Mutants count }} & & \multicolumn{6}{|c|}{ Groups } & \multicolumn{2}{|l|}{ T-Test } \\
\hline & & & \multicolumn{3}{|c|}{ Group I } & \multicolumn{3}{|c|}{ group II } & $\mathrm{t}$ & P-value \\
\hline \multirow{2}{*}{\multicolumn{2}{|c|}{ Baseline }} & Range & 4.6 & - & 5.08 & 4.48 & - & 5.18 & \multirow{2}{*}{0.635} & \multirow{2}{*}{0.529} \\
\hline & & Mean \pm SD & 4.90 & \pm & 0.15 & 4.94 & \pm & 0.20 & & \\
\hline \multirow{2}{*}{\multicolumn{2}{|c|}{ After 7 Days }} & Range & 4 & - & 5 & 3.3 & - & 4.7 & \multirow{2}{*}{-4.596} & \multirow{2}{*}{$0.001 * *$} \\
\hline & & Mean \pm SD & 4.75 & \pm & 0.30 & 4.11 & \pm & 0.54 & & \\
\hline \multirow{2}{*}{\multicolumn{2}{|c|}{ After 15 Days }} & Range & 3.7 & - & 4.95 & 2.7 & - & 4.48 & \multirow{2}{*}{-6.374} & \multirow{2}{*}{$0.001 * *$} \\
\hline & & Mean \pm SD & 4.41 & \pm & 0.49 & 3.36 & \pm & 0.54 & & \\
\hline \multirow{2}{*}{ B-7D } & Differences & Mean \pm SD & 0.14 & \pm & 0.37 & 0.82 & \pm & 0.48 & & \\
\hline & Paired Test & P-value & \multicolumn{3}{|c|}{0.097} & \multicolumn{3}{|c|}{$0.001 * *$} & & \\
\hline \multirow{2}{*}{ B-15D } & Differences & Mean \pm SD & 0.49 & \pm & 0.53 & 1.57 & \pm & 0.53 & & \\
\hline & Paired Test & P-value & \multicolumn{3}{|c|}{$0.001 * *$} & \multicolumn{3}{|c|}{$0.001 * *$} & & \\
\hline \multirow{2}{*}{$7-15 \mathrm{D}$} & Differences & Mean \pm SD & 0.35 & \pm & 0.43 & 0.75 & \pm & 0.34 & & \\
\hline & Paired Test & $\mathrm{P}$-value & \multicolumn{3}{|c|}{$0.002 * *$} & \multicolumn{3}{|c|}{$0.001 * *$} & & \\
\hline
\end{tabular}

The group $I=$ Chlorhexidine group, group $I I=$ Sodium Hexametaphosphate group

$P$-value $>0.05$ Non significant $* P$-value $\leq 0.05$ Significant 


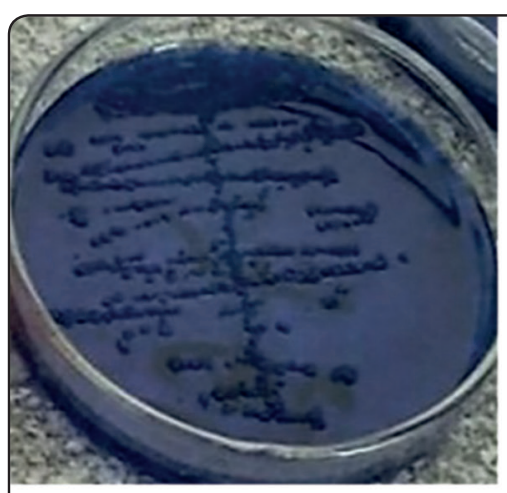

Base line

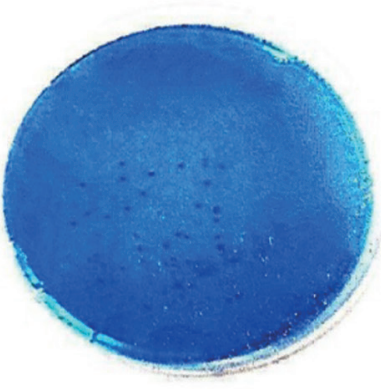

Day 7

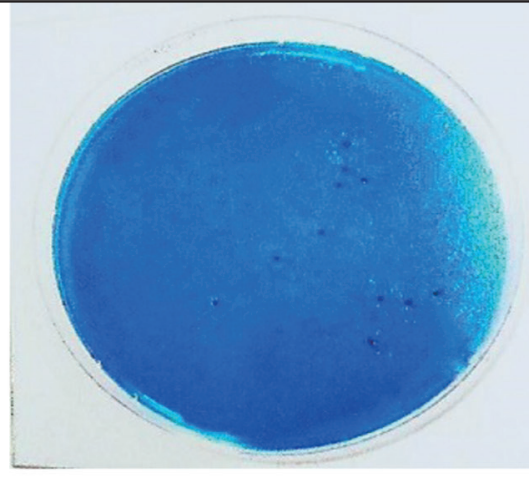

Day 15

Fig. (3) showing Streptococcus mutans colony growth on Mitis salivarius bacitracin agar (MSB) at base line, day 7 and day 15 (group I).

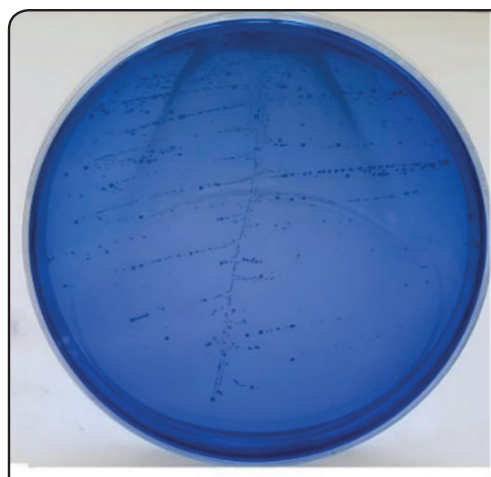

Base line

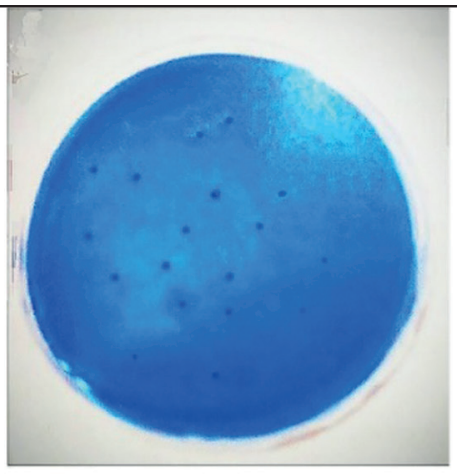

Day 7

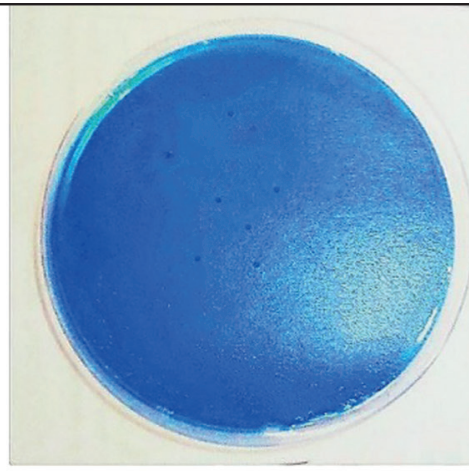

Day 15

Fig. (4) showing Streptococcus growth colony on Mitis salivarius bacitracin agar (MSB) at base line, day 7 and day 15 (group II).

\subsection{Lactobacillus count:}

The mean value of Lactobacillus count in both group I and group II showed a highly statistically significant decrease ${ }^{* *}$ from 7 days to 15 days and from baseline to 15 days as shown in table (4) and figures $(5,6)$.
In between groups, there was no statistical significant difference in the mean value of Lactobacillus count when comparing between group II and group I at all evaluation periods (after 7 days and 15 days) as shown in table (4). 
TABLE (4): Comparison between Lactobacillus count in group I and group II measured at different times of evaluation.

\begin{tabular}{|c|c|c|c|c|c|c|c|c|c|c|}
\hline \multirow{2}{*}{\multicolumn{2}{|c|}{ Lactobacillus count }} & & \multicolumn{6}{|c|}{ Groups } & \multicolumn{2}{|c|}{ T-Test } \\
\hline & & & \multicolumn{3}{|c|}{ Group I } & \multicolumn{3}{|c|}{ Group II } & $\mathrm{t}$ & P-value \\
\hline \multirow{2}{*}{\multicolumn{2}{|c|}{ Baseline }} & Range & 3.7 & - & 4.9 & 4 & - & 5 & \multirow{2}{*}{1.579} & \multirow{2}{*}{0.123} \\
\hline & & Mean \pm SD & 4.44 & \pm & 0.46 & 4.64 & \pm & 0.32 & & \\
\hline \multirow{2}{*}{\multicolumn{2}{|c|}{ After 7 Days }} & Range & 3.3 & - & 4.88 & 2.99 & - & 4.7 & \multirow{2}{*}{-1.901} & \multirow{2}{*}{0.065} \\
\hline & & Mean \pm SD & 4.25 & \pm & 0.51 & 3.90 & \pm & 0.63 & & \\
\hline \multirow{2}{*}{\multicolumn{2}{|c|}{ After 15 Days }} & Range & 2.7 & - & 3.7 & 2.7 & - & 3.48 & \multirow{2}{*}{-0.951} & \multirow{2}{*}{0.348} \\
\hline & & Mean \pm SD & 3.07 & \pm & 0.4 & 2.97 & \pm & 0.27 & & \\
\hline \multirow{2}{*}{ B-7D } & Differences & Mean \pm SD & 0.20 & \pm & 0.20 & 0.74 & \pm & 0.36 & & \\
\hline & Paired Test & P-value & \multicolumn{3}{|c|}{$0.001 * *$} & \multicolumn{3}{|c|}{$0.001 * *$} & & \\
\hline \multirow{2}{*}{ B-15D } & Differences & Mean \pm SD & 1.37 & \pm & 0.58 & 1.67 & \pm & 0.35 & & \\
\hline & Paired Test & P-value & \multicolumn{3}{|c|}{$0.001 * *$} & \multicolumn{3}{|c|}{$0.001 * *$} & & \\
\hline \multirow{2}{*}{$7-15 \mathrm{D}$} & Differences & Mean \pm SD & 1.17 & \pm & 0.61 & 0.93 & \pm & 0.65 & & \\
\hline & Paired Test & $\mathrm{P}$-value & \multicolumn{3}{|c|}{$0.001 * *$} & \multicolumn{3}{|c|}{$0.001 * *$} & & \\
\hline
\end{tabular}

The group I = Chlorhexidine group, group II = Sodium Hexametaphosphate group

P-value $>0.05$ Non significant

*P-value $\leq 0.05$ Significant

**P-value $<0.01$ Highly Significant

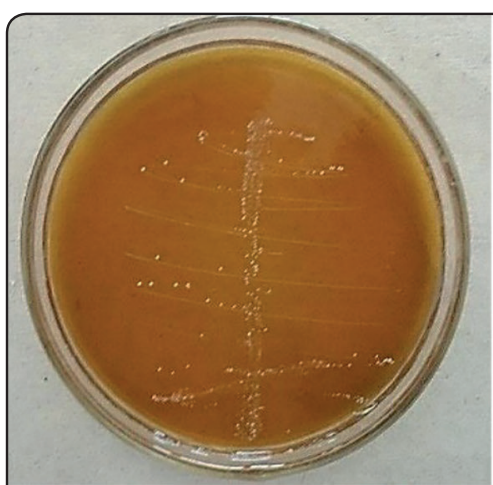

Base line

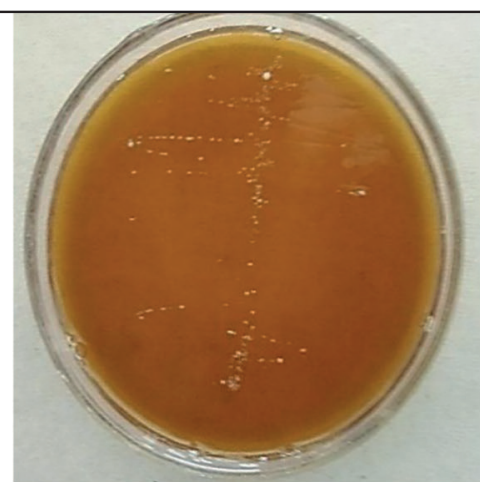

Day 7

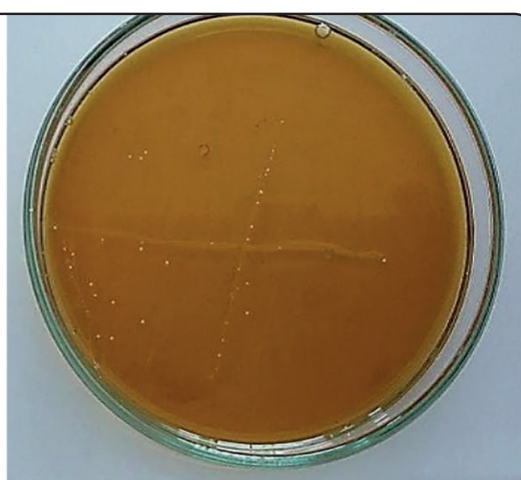

Day 15

Fig. (5) Showing Lactobacillus colony growth on Rogosa agar at base line, day 7 and day 15 (group I). 


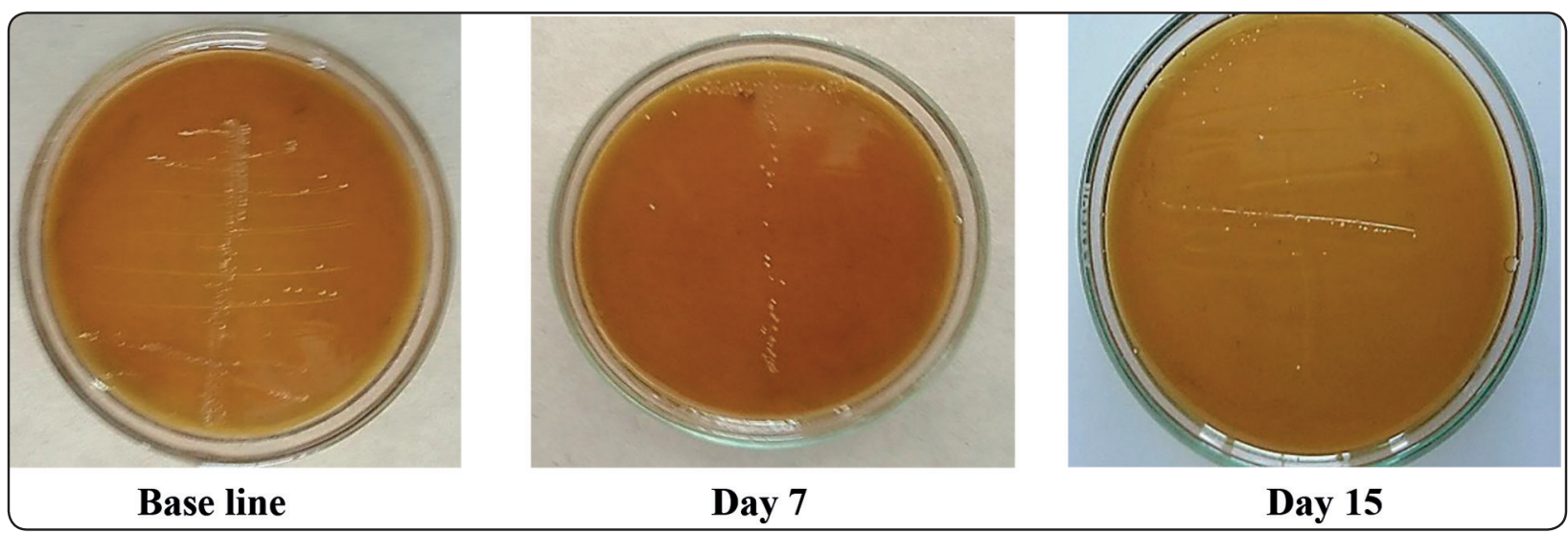

Fig. (6) showing Lactobacillus colony growth on Rogosa agar at base line, day 7 and day 15 (group II).

\section{DISCUSSION}

Dental plaque is a deposition that comprised of numerous living species of microorganisms embedded in an extracellular matrix. Formation of dental plaque is a progressive and dynamic process, which may result in the establishment of caries and gingivitis. Streptococcus mutans and lactobacilli are the cheif components of dental plaque. ${ }^{(22)}$

In order to prevent mouth diseases, plaque control is acheived by regular mechanical means and chemical agents, which act specifically against those microorganisms. ${ }^{(23)}$

Chlorhexidine was used as a mouthwash because it is considered the gold standard anti plaque agent against which efficacy of other anti-plaque and antigingivitis agents is measured. In addition, it gives immediate bactericidal and prolonged bacteriostatic actions due to adsorption onto the pellicle-coated enamel surface. ${ }^{24,25)}$

In this study, Sodium Hexametaphosphate (SHMP) was used because it is a non-combustible material with no significant environmental effects. It has a low oral toxicity and may cause minor irritation to skin, eyes and respiratory tract. ${ }^{(26)}$

Clinical results of this study demonstrated that gingival and Turesky et al Modified Quigley Hein Plaque indices scores among treated children with SHMP mouth rinse had statistical significant improvement compared to the group treated with chlorhexidine mouth rinse at all evaluation periods (7 days and 15 days).

The effect of chlorhexidine on plaque and its property of slow release have made it as the panacea in the adjunctive treatment to gingivitis. Chlorhexididne being cationic prevents pellicle formationandisbacteriostatic at lowerconcentrations and bactericidal at higher concentrations. ${ }^{27)}$

Bellamy et al. ${ }^{(28)}$ stated that (SHMP) when added to a stabilized stannous fluoride dentifrice provides the additional benefits of prevention of calculus formation, stain removal and reduction of stain formation and plaque formation.

Microbiological results of this study revealed that the mean value of $S$. mutans count showed a statistical significant decrease when comparing between II and group I at all evaluation periods (7 days and 15 days).This may be due to the potent antimicrobial activity of SHMP.

Antibacterial effect of SHMP 7\% mouthwash against $S$. mutans and lactobacillus were better than that produced by chlorhexidine $0.2 \%$ mouthwash.

Many studies showed that (SHMP) inhibits the growth of streptococci mutans resulting in a decrease of plaque formation and dental caries. ${ }^{(29)}$ 
On other hands, SHMP does not generally cause any adverse effect on the body when used locally and orally within the range of minimum inhibitory concentrations (MICs) determined for various bacteria. ${ }^{(30)}$

In addition, Hacchou et al. ${ }^{(31)}$ found that SHMP can stimulate bone formation. Thus, SHMP seems to be a promising substance for treatment of periodontal diseases and promoting bone regeneration.

These results were in agreement with Murphy et al. ${ }^{(32)}$, Da Camara et al. (33) who proved that SHMP is characterized by potent, and various biological properties including efficient anti-microbial and anti-biofilm actions. SHMP probably have multiple mechanisms of antibacterial action.

The antimicrobial effect of SHMP can be explained by a mechanism suggested by Maier et al. (34) as SHMP may inhibit the microorganisms by forming potentially inhibitory compounds (e.g., superoxide) or disrupting intracellular metabolism or protein folding. ${ }^{(35)}$

In addition, Shibata et al. ${ }^{(36)}$ and Knabel et al. (37) reported that the antibacterial effect of SHMP against Gram-positive bacteria, including Streptococci mutans, is related to its ability to chelate divalent cations resulting in inhibition of cell division and loss of cell wall integrity. SHMP induces direct lysis of Staphylococcus aureus ( $S$. aureus) by chelation of structurally essential metal ions in their membranes. ${ }^{(38,39)}$

Also, the antimicrobial action of SHMP is related to its capacity to increase the permeability of the bacteria and glucose transport when it links to the $\mathrm{Mg}+$ present in the outer membrane. ${ }^{(40)}$

These results agreed with an in vitro study carried out by Post et al. ${ }^{(41)}$ in which the influence of SHMP on selected bacteria was assessed. The results showed that most Gram-positive bacteria were prevented from growing on medium containing $0.1 \%$ SHMP and Gram-negative bacteria were capable of growing in higher concentrations even up to $10 \%$ SHMP.

In addition, another study in 2008 carried out by Obritsch et al. ${ }^{(42)}$ in which the sensititvity of Gramnegative (Escherichia coli [E. coli] and Salmonella Typhimurium) and Gram-positive (Bacillus subtilis, Staphylococcus aureus, Lactobacillus plantarum and Listeria monocytogenes) spoilage and pathogenic bacteria to different members of long-chain polyphosphates including SHMP was tested. The results showed that Gram-positive bacteria are more sensitive to polyphosphates than are Gram-negative bacteria, possibly because of the differences in cell wall structure.

\section{CONCLUSIONS}

1- SHMP mouthwash at a concentration of $7 \%$ had superior antibacterial effects.

2-SHMP7\% mouthwash improved the clinical parameters than chlorhexidine $0.2 \%$ mouthwash (gingival index scores and Turesky et al Modified Quigley Hein Plaque Index scores).

3-SHMP7\% mouthwash decreased the microbial count of Streptococcus mutans and Lactobacillus species than chlorhexidine $0.2 \%$ mouthwash.

\section{Limitations of the study}

1- Selection of the patients with the inclusion criteria was difficult and took a long time.

- Chemical preparation of mouthwashes was difficult especially SHMP mouth wash.

- Media used for isolation, identification and colony counts of Streptococcus mutans and Lactobacillus species were not available.

- The disclosing agent was not present in Egypt and was brought from Germany. 


\section{REFERENCES}

1. Seneviratne CJ, Zhang CF, Samaranayake LP. Dental plaque biofilm in oral health and disease. Chin J Dent Res. 2011;14(2):87-94. https://www.ncbi.nlm.nih.gov/ pubmed/HYPERLINK "https://www.ncbi.nlm.nih.gov/ pubmed/22319749”22319749

2. Jafer M, Patil S, Hosmani J, Bhandi SH, Chalsserry EP, Anil S. Chemical plaque control strategies in the prevention of biofilm-associated oral diseases. J Contemp Dent Pract. 2016 Apr 1;17(4):337-43. https://www.ncbi.nlm. nih.gov/pubmed/HYPERLINK "https://www.ncbi.nlm. nih.gov/pubmed/27340170"27340170

3. Teles RP, Teles FR. Antimicrobial agents used in the control of periodontal biofilms: effective adjuncts to mechanical plaque control? Braz Oral Res. 2009;23(1):39-48. https:// www.ncbi.nlm.nih.gov/pubmed/HYPERLINK "https:// www.ncbi.nlm.nih.gov/pubmed/19838557”19838557

4. Rashed HT. Evaluation of the effect of hydrogen peroxide as a mouthwash in comparison with chlorhexidine in chronic periodontitis patients: A clinical study. J Int Soc Prev Community Dent. 2016;6(3):206-12. https://www.ncbi.nlm.nih.gov/pmc/articles/PMCHYPERLINK "https://www.ncbi.nlm.nih.gov/pmc/articles/ PMC4916793/"4916793HYPERLINK "https://www. ncbi.nlm.nih.gov/pmc/articles/PMC4916793/"/DOI: 10.4103/2231-0762.183114

5. Mirzadeh A, Rahmani S, Sirjani M, Mirzadeh A, Salahi SA. A comparative study on the effect of $0.2 \%$ chlorhexidine mouthwash and $0.2 \%$ chlorhexidine gel on gingivitis and plaque accumulation. Bull Env Pharmacol. Life Sci. 2014;3(4):140-44. http://www.bepls.com

6. Vinod KS, Sunil KS, Sethi P, Bandla RC, Singh S, Patel D. A novel herbal formulation versus chlorhexidine mouthwash in efficacy against oral microflora. J Int Soc Prev Community Dent. 2018 Mar-Apr; 8(2):184-90. https://www.ncbi.nlm.nih.gov/pmc/articles/PMCHYPERLINK "https://www.ncbi.nlm.nih.gov/pmc/articles/ PMC5946529/"5946529HYPERLINK “https://www.ncbi. nlm.nih.gov/pmc/articles/PMC5946529/"/

7. Danelon M, Takeshita EM, Peixoto LC, Sassaki KT, Debem ACB. Effect of fluoride gels supplemented with sodium trimetaphosphate in reducing demineralization. Clin Oral Investig. 2014 May;18:1119-127. https://www.ncbi. nlm.nih.gov/pubmed/24061604
8. Schiff T, Saletta L, Baker RA, Winston JL, He T. Desensitizing effect of a stabilized stannous fluoride/Sodium hexametaphosphate dentifrice. Compend Contin Educ Dent. 2005 Sep; 26:35-40. https://www.ncbi.nlm.nih.gov/ pubmed/HYPERLINK "https://www.ncbi.nlm.nih.gov/ pubmed/16999008”16999008

9. Vaara M. Agents that increase the permeability of the outer membrane. Microbiol Rev. 1992 Sep; 56:395-411. https:// www.ncbi.nlm.nih.gov/pubmed/HYPERLINK "https:// www.ncbi.nlm.nih.gov/pubmed/1406489”1406489

10. Liu H, Segreto VA, Baker RA, Vastola KA, Ramsey LL, Gerlach RW. Anticalculus efficacy and safety of a novel whitening dentifrice containing sodium hexametaphosphate: A controlled six month clinical trial. J Clin Dent. 2002;13(1):25-28. https://www.ncbi.nlm.nih.gov/ pubmed/HYPERLINK "https://www.ncbi.nlm.nih.gov/ pubmed/11507928"11507928

11. Surya LS, Elianora D, Fitriana A. Effective methods of brushing teeth on reducing plaque score at the fifth Class of semen padang elementary schooling indarung village lubukkilangan subdistrict,Indonesia. IJSBAR. 2015;22(1):281-86. http://gssrr.org/index.php?journal

12. Priya BM, Anitha V, Shanmugam M, Ashwath B, Suganthi D. Sylva SD, et al. Efficacy of chlorhexidine and green tea mouthwashes in the management of dental plaque-induced gingivitis: A comparative clinical study. Contemp Clin Dent. 2015 Oct-Dec;6(4):505-9. https://www.ncbi.nlm.nih.gov/pmc/articles/PMCHYPERLINK "https://www.ncbi.nlm.nih.gov/pmc/articles/ PMC4678549/"4678549HYPERLINK "https://www. ncbi.nlm.nih.gov/pmc/articles/PMC4678549/"/ DOI: 10.4103/0976-237X.169845

13. Allen LV, Popovich NG, Ansel HC. Ansel's Pharmaceutical Dosage Forms and Drug Delivery Systems. 8th ed. Baltimore, Md: Lippincott Williams \& Wilkins; 2005.71 p.

14. Löe H,Silness J. Periodontal disease in pregnancy I. Prevalence and severity.Acta Odontol Scand.1963 Dec;21:533-51.https:// www.ncbi.nlm.nih.gov/pubmed/HYPERLINK "https:// www.ncbi.nlm.nih.gov/pubmed/14121956"14121956 DOI: $10.3109 / 00016356309011240$

15. Turesky S, Gilmore ND, Glickman I. Reduced plaque formation by the chloromethyl analogue of victamine C. J Periodontol. 1970 Jan;41(1):41-3. https://www.ncbi. nlm.nih.gov/pubmed/HYPERLINK "https://www.ncbi. nlm.nih.gov/pubmed/5264376"5264376 DOI: 10.1902/ jop.1970.41.41.41 
16. Hamada S, Slade HD. Biology, immunology and cariogenicity of Streptococcus mutans. Microbiol Rev. 1980;44:331-84. https://www.ncbi.nlm.nih.gov/pmc/articles/PMCHYPERLINK “https://www.ncbi.nlm.nih.gov/ pmc/articles/PMC373181/"373181HYPERLINK “https:// www.ncbi.nlm.nih.gov/pmc/articles/PMC373181/”/

17. Ma Y, Marquis RE. Thermophysiology of Streptococcus mutans and related Lactic acid bacteria. Antonie Van Leeuwenhoek. 1997 Aug;72(2):91-100. https://www.ncbi.nlm.nih. gov/pubmed/HYPERLINK "https://www.ncbi.nlm.nih.gov/ pubmed/9298187”9298187 DOI: 10.1023/a:1000290426248

18. Takada K, Hayashi K, Sasaki K, Sato T, Hirasawa M. Selectivity of MitisSalivarius agar and a new selective medium for oral Streptococci in dogs. J Microbiol Methods. 2006 Sep;66(3):460-5. https://www.ncbi.nlm.nih.gov/ pubmed/HYPERLINK "https://www.ncbi.nlm.nih.gov/ pubmed/16522335"16522335

19. Salminen S, Wright AV. Lactic Acid Bacteria: Microbiological and Functional Aspects. 3th ed. Boca Raton FL: CRC Press; 2004. 656 p

20. Rogosa M, Mitchell J, Wiseman R. A selective medium for the isolation and enumeration of oral and fecal Lactobacilli. J Bacteriol. 1951 Jul;62(1):132-3. https://www.ncbi. nlm.nih.gov/pubmed/HYPERLINK "https://www.ncbi. nlm.nih.gov/pubmed/14861168”14861168

21. Murry PR, Baronet EJ. Manual of Clinical Microbiology. 8th ed. Washington D.C. American Society for Microbiology; 2003.

22. Sundas $S$, RaoA. Comparativeevaluation of effect of chlorhexidine and sodium fluoride mouthwashes on plaque. J Nepal Health Res Counc. 2015 May-Aug;13(30):133-7. https:// www.ncbi.nlm.nih.gov/pubmed/HYPERLINK "https:// www.ncbi.nlm.nih.gov/pubmed/26744198”26744198

23. Haas AN, Reis A, Lemos CA, Pnnuti CM, Escobar E, Almeida ER. Daily biofilm control and oral health: An epidemiological challenge consensus - Brazilian advisory panel in oral health. Braz J Periodontol. 2012;22(3):40-46. https://www.ncbi.nlm.nih.gov/pubmed/ 23318756

24. Renuka S, Muralidharan NP. Compraison in benefits of herbal mouthwashes with chlorhexidine mouthwash: A review. Asian J Pharm Clin Res. 2017;10(2):3-7. https:// www.researchgate.net/publication/HYPERLINK "https:// www.researchgate.net/publication/316506837_Comparison_in_benefits_of_herbal_mouthwashes_with_chlorhexidine_mouthwash_A_review"316506837
25. Shah S, Bargale S, Dave BH, Deshpande A, Kariya PB, Karri A. Comparison of antimicrobial efficacy of (between) $0.2 \%$ chlorhexidine and herbal mouthwash on salivary Streptococcus mutans: A randomized controlled pilot study. Contemp Clin Dent. 2018;9(3): 440-5. https://www. ncbi.nlm.nih.gov/pubmed/30166841 DOI: $10.4103 / \mathrm{ccd}$. ccd_264_18.

26. Baig A, He T, Buisson J, Sagel L, Suszcynsky-Meister E, White DJ. Extrinsic whitening effects of sodium hexametaphosphate- A review including a dentifrice with stabilized stannous fluoride. Compend Contin Educ Dent. 2005 Sep;26(1):47-53. https://www.ncbi.nlm.nih.gov/ pubmed/HYPERLINK "https://www.ncbi.nlm.nih.gov/ pubmed/16999010"16999010

27. Arunachalam LT, Sudhakar U, Vasanth J, Khumukchum S, Selvam VV. Comparison of anti-plaque and anti-gingivitis effect of curcumin and chlorhexidine mouth rinse in the treatment of gingivitis: A clinical and biochemical study. J Indian Soc Periodontol. 2017 Nov-Dec; 21(6):478-83. https://www.ncbi.nlm.nih.gov/ pubmed/HYPERLINK "https://www.ncbi.nlm.nih.gov/ pubmed/29551867”29551867

28. Bellamy PG, Khera N, Day TN, Barker ML, Mussett AJ. A randomized clinical trial to compare plaque inhibition of a sodium fluoride/potassium nitrate dentifrice versus a stabilized stannous fluoride/ sodium hexametaphosphate dentifrice. J Contemp Dent Pract. 2009 Mar 1;10(2):1-9. https:// www.ncbi.nlm.nih.gov/pubmed/HYPERLINK "https:// www.ncbi.nlm.nih.gov/pubmed/19279966"19279966

29. Mankodi S, Bartizek RD, Winston JL, Biesbrock AR, McClanahan SF, He T. Anti-gingivitis efficacy of a stabilized $0.454 \%$ Stannous Fluoride/Sodium Hexametaphosphate dentifrice: A controlled 6-month clinical trial. J Clin Periodontol. 2005 Jan;32(1):75-80. https://www.ncbi.nlm.nih. gov/pubmed/HYPERLINK "https://www.ncbi.nlm.nih. gov/pubmed/15642062"15642062

30. Lanigan RS. Final report on the safety assessment of sodium metaphosphate, sodium trimetaphosphate, and sodium hexametaphosphate. Int J Toxicol. 2001;20(3):75-89. https:// www.ncbi.nlm.nih.gov/pubmed/HYPERLINK "https://www. ncbi.nlm.nih.gov/pubmed/11766135"11766135

31. Hacchou Y, Uematsu T, Ueda O, Usui Y, Uematsu S, Takahashi M, et al. Inorganic polyphosphate: A possible stimulant of bone formation. J Dent Res. 2007 Sep;86(9):893-7. https:// www.ncbi.nlm.nih.gov/pubmed/HYPERLINK "https://www. ncbi.nlm.nih.gov/pubmed/17720862"17720862 
32. Murphy J, Beighton D, Clark D, Bartlett D. The potential for sodium hexametaphosphate (SHMP) found in common children drinks to limit acid production in the oral biofilm. J Dent. 2007 Mar;35(3):214-7. https://www.ncbi.nlm.nih. gov/pubmed/HYPERLINK "https://www.ncbi.nlm.nih. gov/pubmed/16997450”16997450

33. Da Camara DM, Miyasaki ML, Danelon M, Sassaki KT, Delbem AC. Effect of low-fluoride toothpastes combined with hexametaphosphate on in vitro enamel demineralization. J Dent. 2014 Mar;42(3):256-62. https://www. ncbi.nlm.nih.gov/pubmed/HYPERLINK "https://www. ncbi.nlm.nih.gov/pubmed/24333957"24333957 DOI: 10.1016/j.jdent.2013.12.002

34. Maier SK, Scherer S, Loessner MJ. Long-chain polyphosphate causes cell lysis and inhibits Bacillus cereus septum formation which is dependent on divalent cations. Appl Environ Microbiol. 1999 Sep;65(9):3942-9. https://www. ncbi.nlm.nih.gov/pubmed/HYPERLINK "https://www. ncbi.nlm.nih.gov/pubmed/10473399”10473399

35. Chambert R, Petit-Glatron MF. Anionic polymers of Bacillus subtilis cell wall modulate the folding rate of secreted proteins. FEMS Microbiol Lett. 1999 Oct1;179(1):43-7. https://www.ncbi.nlm.nih.gov/ pubmed/HYPERLINK "https://www.ncbi.nlm.nih.gov/ pubmed/10481084"10481084 DOI: 10.1111/j.15746968.1999.tb08705.x

36. Shibata H, Morioka T. Antibacterial action of condensed phosphates on the bacterium Streptococcus mutans and experimental caries in the hamster. Arch Oral Biol. 1982;27(10):80916. https://www.ncbi.nlm.nih.gov/pubmed/HYPERLINK "https://www.ncbi.nlm.nih.gov/pubmed/6961893"6961893 DOI: 10.1016/0003-9969(82)90034-6

37. Knabel S, Walker H, Harman P. Inhibition of Aspergillus flavus and selected gram-positive bacteria by chelation of essential metal cations by polyphosphates. J Food Prot. 1991 May;54(5):360-5. https://www.ncbi.nlm.nih.gov/ pubmed/HYPERLINK "https://www.ncbi.nlm.nih.gov/ pubmed/31051558”31051558 DOI: 10.4315/0362-028X54.5 .360

38. Lee RM, Hartman PA, Stahr HM, Olson DG, Williams FD. Antibacterial mechanism of long-chain polyphosphates in Staphylococcus aureus. J Food Prot. 1994 Apr;57(4):28994. https://www.ncbi.nlm.nih.gov/pubmed/HYPERLINK "https://www.ncbi.nlm.nih.gov/pubmed/31113131"31113131 DOI: $10.4315 / 0362-028 X-57.4 .289$

39. Moon JH, Park JH, Lee JY. Antibacterial Action of Polyphosphate on Porphyromonas gingivalis. Antimicrob Agents Chemother. 2011 Feb;55(2):806-12. https://www. ncbi.nlm.nih.gov/pubmed/HYPERLINK "https://www. ncbi.nlm.nih.gov/pubmed/21098243"21098243 DOI: 10.1128/AAC.01014-10.

40. Da Camara DM, Pessan JP, Francati TM, Santos Souza JA, Danelon M, Delbem AC. Synergestic effect of fluoride and sodium hexametaphosphate in toothpaste on enamel demineralization in situ.J Dent. 2015 Oct;43(10):1249-54.https:// www.ncbi.nlm.nih.gov/pubmed/HYPERLINK "https:// www.ncbi.nlm.nih.gov/pubmed/26299931”26299931 DOI: $10.1016 / j . j d e n t .2015 .08 .007$

41. Post FJ, Krishnamurty GB, Flanagan MD. Influence of sodium hexametaphosphate on selected bacteria. Appl Microbiol. 1963 Sep;11:430-5.https://www.ncbi.nlm.nih.gov/ pubmed/14063787

42. Obritsch JA, Ryu D, Lampila LE, Bullerman LB. Antibacterial effects of long-chain polyphosphates on selected spoilage and pathogenic bacteria. J Food Prot. 2008 Jul; 71(7):1401-5. https://www.ncbi.nlm.nih.gov/ pubmed/18680939 DOI: 10.4315/0362-028x-71.7.1401 